Dhaka Univ. J. Biol. Sci. 19(1): 47-52, 2010 (January)

\title{
INFESTATION OF ENTAMOEBA HISTOLYTICA AMONG THE CHILDREN OF MIRPUR COHORT AREA, DHAKA
}

\author{
Fatema Rahman, Hamida Khanum*, Md. Hafiz Uddin and Rashidul Haque ${ }^{1}$ \\ Department of Zoology, University of Dhaka, Dhaka-1000, Bangladesh
}

Key words: Infestation, Entamoeba histolytica, Stool, Dipstick, ELISA

\begin{abstract}
Entamoeba histolytica is one of the deadly species of protozoan parasites and is associated with pathological abnormalecies in liver and large bowel in human body. To detect the prevalence of $E$. histolytica, 350 stool samples were examined by a number of diagnostic techniques. Routine microscopic examination detected $27.3 \%$ prevalence of $E$. histolytica in symptomatic stool samples and $8.6 \%$ in asymptomatic stool samples. Dipstick test detected the same prevalence (27.3\%) like that of microscopy in case of symptomatic stool samples, but $10.32 \%$ was in asymptomatic samples. ELISA detected 9.09\% prevalence in symptomatic samples and $3.5 \%$ in asymptomatic samples. The females were found more infected than males and the most infective group detected by different techniques was 9-10 years children.
\end{abstract}

\section{Introduction}

Bangladesh is a tropical country. Clinical amoebiasis is most prevalent in tropical and subtropical areas. It is a great public health problems in rural and urban areas with a wide spread endemicity. Low socio-economic conditions, poor hygienic habits and the most important is lack of health education allow for transmission of the amoebic infection.

Amoebiasis is a significant health problem world wide, especially in developing countries. It is presently one of the three most common causes of death from parasitic diseases. It has also been estimated that, approximately 500 million individuals are infected with $E$. histolytica each year and only about $10 \%$ experience symptomatic disease.(1,2) An estimated 40,000-100,000 people die of invasive amoebiasis annually. ${ }^{(3)}$

The distribution of the parasite is world wide, although the preponderance of morbidity and mortality is experienced in Central and South America, Africa, and India. ${ }^{(4)}$ Amoebiasis, defined as asymptomatic, invasive intestinal or extraintestinal disease due to $E$. histolytica infection, is one of the most common parasitic infections world wide, Asymptomatic cyst is the most frequent manifestation of intestinal Entamoeba infection and $90 \%$ of E. histolytica infections are asymptomatic. ${ }^{(5)}$

*Corresponding author.<hamida_khanum@yahoo.com>. ${ }^{1}$ Laboratory Sciences Division at the International Centre for Diarrhoeal Disease Research, Bangladesh, Dhaka, Bangladesh. 
There are four species of Entamoeba (E. histolytica, E. dispar, E. coli, E. hartmanni) may regularly be found in human large bowel, only one of which is pathogenic. There are also a few rare species: "atypical," "low temperature" or "Laredo" strains of $E$. histolytica, now known to be the normally free-living species which are E. moshkovski, ${ }^{(6)} E$. polecki, E. chattoni and E. gingivalis.

The cysts of $E$. coli and $E$. hartmanni may be distinguished by light microscopy applying well-understood criteria from those of $E$. histolytica and $E$. dispar but the later two are indistinguishable from each other. After extensive research and argument, it is generally accepted that, $E$. histolytica actually comprises two genetically distinct but morphologically indistinguishable species. $E$. disper has never been documented to cause colitis or liver abscess, but is responsible for many cases of asymptomatic infection.

Identification and differentiation of E. histolytica and E. dispar in stool sample by microscopy is imprecise. In most of the cases, false-positive result were found due to misidentification of macrophages and nonpathogenic species of Entamoeba. ${ }^{(7)}$

The amoeboid trophozoites can live in the intestinal crypts, feeding on intestinal contents and host tissue, and multiplying by fission. In some cases the trophozoites secrete proteolytic enzymes which destroy the intestinal epithelium allowing the trophozoite to enter the host tissue. These can form large abscesses that may allow the parasite to enter the blood stream and be carried to the liver and other organs. In these extra-intestinal sites the trophozoites also can cause extensive tissue destruction. If the intestinal tissue has been invaded the faeces can be bloody. Secondary bacterial infection can complicate an already severe pathology. Accurate diagnosis of this parasite is important to prevent unnecessary treatment of a nonpathogenic strain, and to ensure treating a pathogenic strain.

The necessity to identify and treat asymptomatic carriers of $E$. histolytica is emphasized by the observation that $10 \%$ of them develop invasive amoebiasis in due courses. ${ }^{(8)}$ Additionally, asymptomatic carriers are more likely to spread the disease than symptomatic persons with invasive disease, as the latter individuals seek medical attention. ${ }^{(9)}$

\section{Materials and Methods}

In total, 350 stool samples were collected from Mirpur area, Dhaka, Bangladesh during July - October, 2005 and the entire study was carried out in the Parasitology Laboratory, Laboratory Sciences Division (LSD) at the International Centre for Diarrhoeal Disease Research, Bangladesh (ICDDR,B) Dhaka.

Stool samples were preserved in $10 \%$ formal saline and also stored the specimens at $-20^{\circ} \mathrm{C}$ which could not be performed within 72 hours of collection. To identify the 
target parasites, microscopic examination was done by direct smear and stained preparation. Dipstick or rapid test was conducted with several supplied antigen detection kits according to the instruction of TechLab, Inc., Blacksburg, VA. The ELISA was used for the detection of $E$. histolytica. The test was performed according to manufacturer's instructions and in this test antibodies were used for the adhesin stool antigen ELISA.

\section{Results and Discussion}

During the study period, fecal specimens of 350 school children of 5 - 12 years were collected from an urban slum in Mirpur, Dhaka, Bangladesh. About 339 samples were found asymptomatic stool samples and 11 were sympomatic (diarrhoeal) in the total samples. Among the collected samples, 29 asymptomatic stool samples were microscopycally positive either, with cysts or trophozoites and 3 sympomatic (Diarrhoeal) stool samples were found positive by microscopy. A total of 11 symptomatic stool samples examined during the study period. Among the examined samples, the prevalence of $E$. histolytica were $27.3 \%$ by microscopy, 9.09 and $27.3 \%$ were by ELISA and Dipstick, respectively (Table 1 ).

Table 1. Comparative prevalence of $E$. histolytica by microscopic examination, Dipstick and ELISA.

\begin{tabular}{lcccc}
\hline $\begin{array}{l}\text { Types of } \\
\text { sample }\end{array}$ & $\begin{array}{c}\text { Total } \\
\text { number of } \\
\text { samples } \\
\text { examined }\end{array}$ & $\begin{array}{c}\text { Prevalence of } \\
\text { E. histolytica by } \\
\text { microscopic } \\
\text { examination (\%) }\end{array}$ & $\begin{array}{c}\text { Prevalence of } \\
\text { E. histolytica by } \\
\text { dipstick test (\%) }\end{array}$ & $\begin{array}{c}\text { Prevalence of } \\
\text { E. histolytica by } \\
\text { ELISA (\%) }\end{array}$ \\
\hline Asymptomatic & 339 & 8.6 & 10.32 & 3.5 \\
Symptomatic & 11 & 27.3 & 27.3 & 9.09 \\
Total & 350 & 9.14 & 10.85 & 3.71 \\
\hline
\end{tabular}

Among 350 stool samples were examined, 171 were male and 179 were female. Out of 179 female samples, 16 were positive and the prevalence of $E$. histolytica was $9.35 \%$ by microscopy. Dipstick test detected 22 stool samples positive and prevalence was $12.29 \%$, while ELISA confirmed 9 positive samples and prevalence was $5.02 \%$. In total male, the prevalence was $9.35 \%$ by microscopy and Dipstick test detected $9.35 \%$ prevalence. The ELISA showed $2.33 \%$ prevalence (Table 2 ).

The stool samples of children were divided into four categories according to their age groups between 5 and 12 years. In both microscopic and dipstick test, the prevalence of $E$. histolytica was same (16.2\%) in 9 - 10 years of children. ELISA detected $7.20 \%$ prevalence in the same group. The lower incidence found in 5-6 years, detected by three different methods (Table 3 ). 
In asymptomatic stool samples, by microscopy examination it was $25 \%$ sensitive and $92 \%$ specific. Dipstick test showed $89 \%$ sensitivity and $96 \%$ specificity. Dipstick test was more sensitive than microscopy when compared with ELISA. Antigen detection tests have proven to be more sensitive and specific than microscopy. ${ }^{(2)}$ Among the symptomatic stool samples, microscopy was $0 \%$ sensitive and $70 \%$ specific. Dipstick showed $66 \%$ sensitivity and $87 \%$ specificity.

Table 2. Comparative prevalence of $E$. histolytica in different sex group by microscopic examination, Dipstick and ELISA.

\begin{tabular}{lcccc}
\hline Sex & $\begin{array}{c}\text { Total } \\
\text { number of } \\
\text { samples }\end{array}$ & $\begin{array}{c}\text { Prevalence of } \\
\text { E. histolytica by micro- } \\
\text { scopic examination }\end{array}$ & $\begin{array}{c}\text { Prevalence of } \\
\text { E. histolytica by } \\
\text { dipstick test (\%) }\end{array}$ & $\begin{array}{c}\text { Prevalence of } \\
\text { E. histolytica by } \\
\text { ELISA (\%) }\end{array}$ \\
\hline Male & 171 & 9.35 & 9.35 & 2.33 \\
Female & 179 & 9.0 & 12.29 & 5.02 \\
\hline
\end{tabular}

Table 3. Prevalence of $E$. histolytica in different age groups by microscopic examination, Dipstick and ELISA.

\begin{tabular}{lcccc}
\hline $\begin{array}{l}\text { Age group } \\
\text { (Years) }\end{array}$ & $\begin{array}{c}\text { Total } \\
\text { number of } \\
\text { samples }\end{array}$ & $\begin{array}{c}\text { Prevalence of } \\
\text { E. histolytica by micro- } \\
\text { scopic examination (\%) }\end{array}$ & $\begin{array}{c}\text { Prevalence of } \\
\text { E. histolytica by } \\
\text { dipstick test (\%) }\end{array}$ & $\begin{array}{c}\text { Prevalence of } \\
\text { histolytica by } \\
\text { ELISA (\%) }\end{array}$ \\
\hline $5-6$ & 50 & 4 & 8 & 6 \\
$7-8$ & 58 & 6.89 & 10.3 & 5.17 \\
$9-10$ & 111 & 16.2 & 16.2 & 7.20 \\
$11-12$ & 131 & 9.16 & 13.07 & 6.10 \\
\hline
\end{tabular}

In total samples, Dipstick test was $87 \%$ sensitive and $96 \%$ specific. ELISA was 9\% sensitive and $96 \%$ specific. The results were comparable with the results of Weinke et al.(10) They studied on 2700 German citizens returning from tropical areas and reported $0.3 \%$ prevalence of $E$. histolytica in their study and the rate was similar to that of $0.7 \%$ among under 5 Sudanese children. Braga et al. ${ }^{(11)}$ and Sultana et al. ${ }^{(12)}$ reported that infection with Entamoeba histolytica increased with the growth of age and females were more likely infected than males. A study of Cross (13) revealed the opposite result where infection rate was higher for males (17\%) than females (11\%).

Muttalib et al. ${ }^{(14)}$ reported $11.07 \%$ prevalence of Entamoeba histolytica in the students of Dhaka University. In 1988, Weinke et al. ${ }^{(15)}$ conducted a study which compared as patients with amoebiasis to non-amoebic diarrhoeal patients at a hospital for tropical diarrhoeal diseases in Dhaka, Bangladesh. The overall case fatality rate for the patients with amoebiasis was $29 \%$ which was significantly higher 
than $11 \%$ for the non-amoebic diarrhoeal controls. The high case of fatality rate was similar (26\%) as reported by Lewis and Antia, ${ }^{(16)}$ for hospitalized patients in Nigeria and $27 \%$ reported by Adams and MacLeode (17) for South African children indicating that amoebiasis is a severe disease that carries a worse prognosis than other endemic diarrhoeal infections.

The world-wide prevalence of E. histolytica has been described as $14.3 \%$ and in Asia 16\%, in America 12\%, and in Africa 17\%.(18) The prevalence of E. histolytica was found to be 0.5 to $38 \%$ in Asia, 0.6 to $37 \%$ in Africa and $0-49 \%$ of in America. ${ }^{(19)}$ Several microscopy-based epidemiological studies in Iran have shown 2.2 to $30 \%$ of Entamoeba infection. Current microscopy-based studies, showed a high prevalence of $E$. histolytica in asymptomatic carriers. This was true even in the tropical areas of the south, where previous surveys showed that up to $30 \%$ of asymptomatic individuals residing in rural areas with poor sanitation were infected by $E$. histolytica / E. dispar.

It can be concluded from the present study that, the prevalence of Entamoeba histolytica detected by the three different techniques was most common in the children of Mirpur cohort area and females were detected more infected than the male children.

\section{References}

1. Trol H, H Marti and N Weiss 1997. Simple differential detection of Entamoeba histolytica and Entamoeba disper in fresh stool specimens by sodium acilate-acetic acid formalin concentration and PCR. J. Clin. Microbiol. 35: 1701-1705.

2. Haque R, IK Ali, S Akther and WA Jr Petri 1998. Comparison of PCR, isoenzyme analysis and antigen detection for diagnosis of Entamoeba histolytica infection. J. Clin. Microbiol. 36: 449-452.

3. Stanley SL 2003. Amoebiasis. The lancet. 361: 1025-1034.

4. Yamada S, R Yamada, Y Pan, Y Mori, S Tsukidate, and K Fujita 1995. Intestinal parasitic infections in natives and residents of Mozambique. Jap. J. Parasitol. 44: 174-175.

5. WHO 1997. Report of a consultation of expertson amoebiasis.Weekly epidemiological report of the World Health Organization. 72: 97-100.

6. Clark CG and LS Diamond 1991.The Laredo strain and other Entamoeba histolytica like amoebae are Entamoeba moshkovskii. Mol. Biochem. Parasitol. 46:11-8.

7. Kebede A, JJ Verweijz, P Beyene and AM Polderman 2004. Misleading microscopy in amoebiasis. Tropical Medicine and International Health. 9(5): 651-652.

8. Gonzalez-ruiz A, R Haque, T Rehman, AA Guirre, A Hall, F Guhl, D C Warhurst and MA Miles 1994. Diagnosis of amoebic dysentery by detection of Entamoeba histolytica fecal antigen by an invasive strain-specific monoclonal antibody-based enzyme-linked immunosorbent assay. J. Clin. Microbiol. 32: 964-970. 
9. Mirelman D, Y Nuchamowitz and T Stolarsky 1997. Comparison of use of enzyme-linked immunosorbent assaybased kits and PCR amplification of rRNA genes for simultaneous detection of Entamoeba histolytica and E. dispar. J. Clin. Microbiol. 35: 240-257.

10. Weinke T, B Friedrich-Janicke, P Hopp and K Janitschke 1990. Prevalence and clinical importance of Entamoeba histolytica in two high-risk groups: travelers returning from the tropics and male homosexuals. J. Infect. Dis. 161: 1029-1031

11. Braga L, AA M Lima, CI Sears, RD Newma, T Wuhib, CA Paiva, RL Guerrant and BJ Mann 1996. Seroepidemiology of Entamoeba histolytica in a slum in Northeastern Brazil. Am. J. Trop. Hyg. 55(6): 693-697.

12. Sultana $\mathrm{Y}, \mathrm{H}$ Khanum and $\mathrm{R}$ Haque 2007. Comparative study of gal/galnac lectin in response to Entamoeba histolytica infection among the preschool children in Bangladesh. Bangladesh J. Zool. 35(1): 33-38.

13. Cross JH 1981. Intestinal parasitic infections in southeast Asia. Southeast Asian J. Trop. Med. Pub. 12(2): 262-271.

14. Muttalib MA, N Islam and JA Ghani 1975. Intestinal parasites in University of Dhakastudents. Am. J. Trop. Med. Hyg. 78: 224-226.

15. Weinke T, B Friedrich, B Janicke and K Janitschke 1988. The importance of Entamoeba histolytica in persons returning from the tropics. Dutch. Med. Wochenschr. 113(17): 678-682.

16. Lewis EA, and AU Antia 1969. Amoebic colitis: review of 295 cases. Trans. R. Soc. Trop. Med. Hyg. 63(5): 633-8.

17. Adams EB and IN MacLeod 1977. Invasive amebiasis. II. Amebic liver abscess and its complications. Medicine 56: 325-334.

18. Belding DL 1965. The parasitic amoeba of man. Text book of Parasitology $4^{\text {th }}$ Edition. Appleton-Century-Crafts, New York. pp. 31-51

19. Walsh J 1988. Prevalence of Entamoeba histolytica infection. In: J.I. Ravdin (ed.), Amebiasis, human infection by Entamoeba histolytica. John Wiley and Sons Inc, New York. pp. 93-105.

(Manuscript received on 20 August, 2008; revised on 18 November, 2008) 